\title{
A MODEL OF FUEL COMBUSTION PROCESS IN THE MARINE RECIPROCATING ENGINE WORK SPACE TAKING INTO ACCOUNT LOAD AND WEAR OF CRANKSHAFT-PISTON ASSEMBLY AND THE THEORY OF SEMI-MARKOV PROCESSES
}

Jerzy Girtler, Prof.

Gdańsk University of Technology, Poland

\begin{abstract}
The article analyses the operation of reciprocal internal combustion engines, with marine engines used as an example. The analysis takes into account types of energy conversion in the work spaces (cylinders) of these engines, loads of their crankshaft-piston assemblies, and types of fuel combustion which can take place in these spaces during engine operation. It is highlighted that the analysed time-dependent loads of marine internal combustion engine crankshaftpiston assemblies are random processes. It is also indicated that the wear of elements of those assemblies resulting from their load should also be considered a random process. A hypothesis is formulated which explains random nature of load and the absence of the theoretically expected detonation combustion in engines supplied with such fuels as Diesel Oil, Marine Diesel Oil, and Heavy Fuel Oil. A model is proposed for fuel combustion in an arbitrary work space of a marine Diesel engine, which has the form of a stochastic four-state process, discrete in states and continuous in time. The model is based on the theory of semi-Markov processes.
\end{abstract}

Keywords: engine load, marine internal combustion engine, probability, semi-Markov process, crankshaft-piston assembly

\section{INTRODUCTION}

The safety of motion of a sea going vessel significantly depends on, among other factors, correct operation of the main engine and auxiliary internal combustion engines on this vessel $[7,13,17]$. The operation of marine engines of this type can be interpreted as the conversion of energy $E(t)$ in their work spaces to produce heat and work, which are then passed to receivers at a given time $t[4,13,15,16]$. What is interesting, in this interpretation the operation of engines of this type (in an evaluating approach) can be expresses by a physical quantity with the attributed numerical value and the unit of measurement bearing the name of joule-second [4].

In Diesel engines, energy conversion $E(t)$ initially consists in chemical conversion $E_{C h}$ of the energy contained in the fuel-air mixture formed in the combustion chamber into the internal energy of the exhaust gas generated during the combustion. The product of this conversion is characterised by thermal energy $E_{C}$. In author's opinion, this form of energy conversion can be referred to as heat. The next form of energy conversion consists in converting the thermal energy $E_{C}$ of the exhaust gas into mechanical energy $E_{M}$ of the crankshaft-piston assembly (Fig. 1). In the same convention, this form of energy conversion can be referred to as work, as it makes it possible for the engine to perform useful work $L_{e}$. This work is an effect of action of the torque $\left(M_{o}\right)$ generated by the crankshaft-piston assembly at given engine revolutions (n) $[1,2,4,5,6,9]$. Hence, the operation of an arbitrary engine can be interpreted as conversion of energy $E(t)$ which leads to 
useful work $L_{e}=f(t)$ done in time $t$. In this interpretation the entire action can be described in the form of the relation [4]:

$D_{L_{e}}=\int_{0}^{t} L_{e}(\tau) \mathrm{d} \tau=2 \pi \int_{0}^{t} n(\tau) M_{o}(\tau) \tau \mathrm{d} \tau=2 \pi \cdot c \int_{0}^{t} n(\tau) p_{e}(\tau) \tau \mathrm{d} \tau$

The above interpretation of engine operation has not only the cognitive but also practical value, as it enables to make distinction between possible engine operation $D_{M}$ and the operation $D_{W}$ required by the user of this engine. The possible operation $D_{M}$ depends on work cycles executed in this engine, which are in turn affected by the technical state of the engine resulting from its wear and by chemical properties of the fuelair mixture formed in the combustion chambers. On the other hand, the required operation $D_{W}$ reflects requirements of the engine user, in terms of energy characteristics which are to be met for the ship to perform successfully its transport task.

Two facts result from the relation (1). The first fact is that the operation of the Diesel engine depends on correct execution of consecutive work cycles, as the average useful pressure $\left(p_{e}\right)$, and, consequently, the average torque $\left(M_{o}\right)$ of this engine depend on how much the real work cycles differ from their theoretical course. The other fact is that the engine is capable of performing its task if the following inequality is fulfilled:

$$
D_{M} \geq D_{W}
$$

Real work cycle execution depends mainly on the course of fuel combustion process in the work spaces (cylinders) of the reciprocal internal combustion engine. The correct course of this process mainly depends on time histories of: combustion pressure - $p_{s}=f_{p}(\alpha)$, combustion temperature $-T_{s}=f_{T}(\alpha)$, heat generation rate $-\mathrm{d} q_{s} / \mathrm{d} \alpha=f_{q}(\alpha)$ and fuel doses delivered to engine cylinders $-G_{p}=f(\alpha)[13,15]$. The combustion in the engine work space can have a quasi-detonation form or even, rather rarely, a detonation form, or a non-detonation (normal) form. The normal combustion can be full (complete and perfect) or partial, i.e. complete, but imperfect, or even incomplete and imperfect $[13,16,17]$. Each type of fuel combustion in cylinders generates different combustion pressures and temperatures. As a consequence, different loads of the crankshaftpiston assembly are observed in engines of this type (Fig. 1). The quasi-detonation combustion is the cause of significant bearing loads, while the imperfect combustion leads to the formation of carbon deposits on combustion chamber elements, in particular on the piston crown. In this context, it would be of high importance to assess the probability of appearance of particular types of combustion. This piece of information can be obtained after modelling the real combustion process in the engine as the stochastic process $\{X(t): t \geq 0\}$, with the values having the form of such states as: $s_{1}-$ full (complete and perfect) combustion, $s_{2}$ - imperfect combustion, $s_{3}$ - incomplete and imperfect combustion, $s_{4}$ - quasi-detonation combustion. This model would enable to assess the probabilities of appearance of particular states: $p_{1}=P\left(s_{1}\right), p_{2}=P\left(s_{2}\right), p_{3}=P\left(s_{3}\right)$ and $p_{4}=$ $P\left(s_{4}\right)$. The proposal to analyse the combustion process in Diesel engine work spaces with the aid of the process $\{X(t)$ : $t \geq 0\}$ as the model results from specific nature of loads of crankshaft-piston assemblies in engines of this type. These loads and the resultant wear of their elements, in both linear and volumetric form, mainly depend on the course of the combustion process in work spaces of these engines $[1,7,9$, $12,13,17]$.

\section{CRANKSHAFT-PISTON ASSEMBLY LOADS IN INTERNAL COMBUSTION ENGINES}

During the operation of marine trunk piston Diesel engines, chemical energy of fuel delivered to the engine work space is initially converted into the internal energy of the exhaust gas generated during the fuel combustion process, and then to the mechanical energy of piston motion. The mechanical energy is passed by the crankshaft-piston assembly to the receiver, for instance to the ship propeller, electric generator, piston compressor, or displacement pump. A sample scheme of energy conversion in the work space of a trunk piston engine and the formation of loads of its crankshaft-piston assembly is shown in Fig. 1.

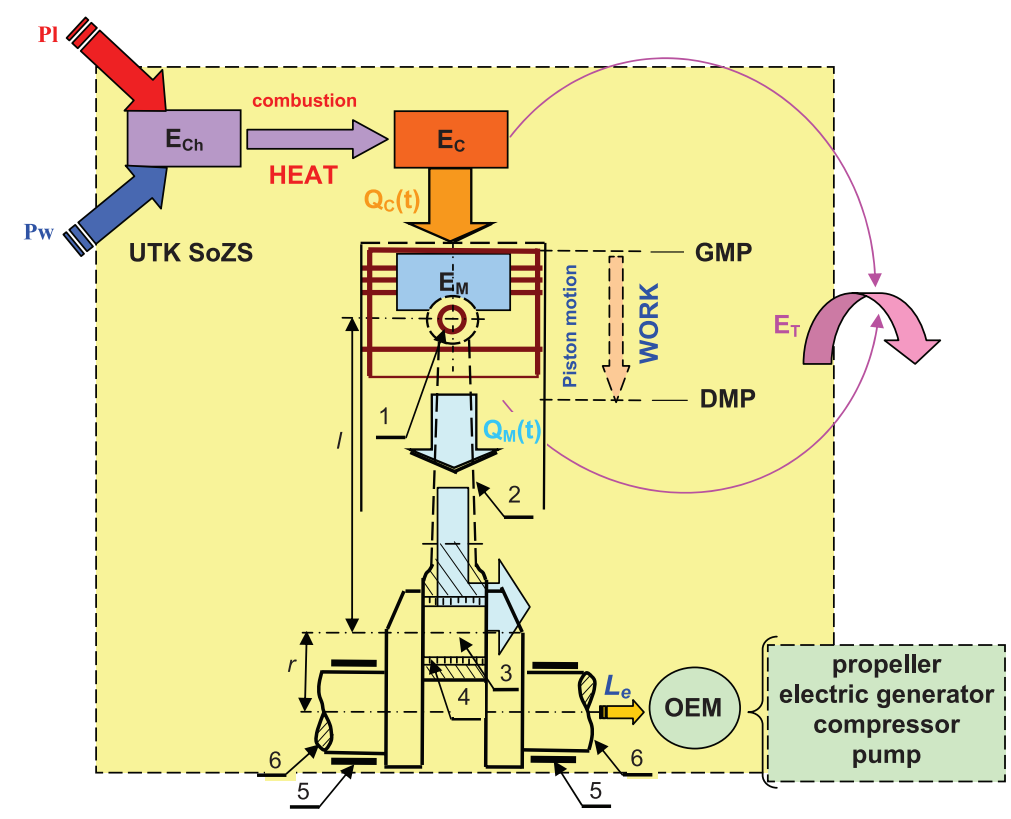

Fig. 1. Sample scheme of energy conversion in a trunk piston Diesel engine with pin connection between piston and connecting rod head: $\mathrm{Pl}$ - fuel, $P w$ - air, $E_{C h}$ - chemical energy, $E_{C}$ - thermal energy, $E_{M}$ - mechanical energy, $E_{T}$ - thermal and mechanical loss energy, UTK SoZS - Diesel engine crankshaft-piston assembly, SoZS - Diesel engine, OEM - mechanical energy receiver (ship propeller, electric generator, compressor, pump), $Q_{c}(t)$ - thermal load at time $t, Q_{M}(t)$ - mechanical load at time $t, G M P$-top dead centre of piston motion, DMP - bottom dead centre of piston motion, $l$ - connecting rod length, $r$-crank radius, 1 - piston pin, 2 - connecting rod, 3 - crankpin, 4 crankshaft bearing bush, 5 - main bearing bush, 6 - main journal 
Part of the energy converted in the engine work spaces is used to perform useful work $\left(L_{e}\right)$, while the remaining part $\left(E_{T}\right)$ is lost (dissipated), according to the second law of thermodynamics [16]. The process is accompanied with time dependent thermal loads $\left(Q_{C}\right)$ and mechanical loads $\left(Q_{M}\right)$ of crankshaft-piston assemblies of those engines.

It is well known from empirical examinations that the loads of engine crankshaft-piston assemblies at time $t$ cannot be precisely predicted $[5,7,8,9]$. Therefore the following hypothesis $\boldsymbol{H}$ can be formulated: „at an arbitrary time $\boldsymbol{t}$ the load of crankshaft-piston assembly of the internal combustion engine is a random variable, as its values recorded in consecutive measurements can only be predicted with certain probability".

The following consequences result from this hypothesis:

- $K_{1}$ - in each work cycle of the engine taking place in a given cylinder we cannot predict precisely the dose $\left(G_{p}\right)$ of fuel injected to the combustion chamber. It can only be predicted with a certain probability, which can be assessed using its point or interval estimation,

- $K_{2}$ - in each work cycle of the engine taking place in a given cylinder we cannot predict precisely the maximum value $\left(p_{\max }\right)$ of the combustion pressure. It can only be predicted with a certain probability, which can be assessed using its point or interval estimation,

- $K_{3}$ - in each work cycle of the engine taking place in a given cylinder we cannot predict precisely the maximum value $\left(T_{\max }\right)$ of the combustion temperature. It can only be predicted with a certain probability, which can be assessed using its point or interval estimation,

- $K_{4}$ - in each work cycle of the engine taking place in a given cylinder we cannot predict precisely the heat generation rate $\left(\mathrm{d} q_{s} / \mathrm{d} \alpha\right)$ during fuel combustion at an arbitrary angular crankshaft position. It can only be predicted with a certain probability, which can be assessed using its point or interval estimation.

The above hypothesis can be verified using the non deductive inference method, bearing the name of reductive inference, which bases on the following scheme:

$$
K_{1}, K_{2}, K_{3}, K_{4} \vdash H
$$

Verification of the hypothesis $(H)$, done via experimental examination of the truth of the above-named consequences $(K, i=1,2,3,4)$, requires acceptance of the truth of the following syntactic implication:

$$
H \Rightarrow K_{i}(i=1,2,3,4)
$$

The logical interpretation of the inference scheme (3) is the following: if experimental verification of consequence $K_{i}(i=$ $1,2,3,4)$ has confirmed its truth, then if the implication (4) is true, then the hypothesis $H$ is also true and can be accepted. The inference carried out in accordance with the scheme (3) does not lead to sure conclusions, but only to probable ones.

It results from the above considerations that during the operation of the engine its thermal and mechanical loads $[2,4,9,11,13,15,17]$, and, consequently, the loads of its crankshaft-piston assemblies at an arbitrary time $t$ should be considered random variables. As a further consequence, the thermal load process and the mechanical loads process should be considered stochastic processes, $\left\{Q_{C}(t) ; t \geq 0\right\}$ and $\left\{Q_{M}(t) ; t \geq 0\right\}$, respectively. These two processes compose the stochastic process of total load $\left\{Q_{D}(t) ; t \geq 0\right\}$ taking place during engine operation. Hence the total load $Q_{D}(t)$ of crankshaftpiston assemblies of an arbitrary internal combustion engine during its operation can be presented as:

$$
Q_{D}(t)=Q_{C}(t)+Q_{M}(t)
$$

where:

In these formulas :

$$
Q_{C}(t)=Q_{\Delta U}(t)+Q_{O}(t)
$$

$Q_{D}(t)$ - total load resulting from engine action $(D)$ at time $t(1)$,

$Q_{C}(t)$ - thermal load carried by engine elements during its operation at time $t$,

$Q_{M}(t)$ - mechanical load connected with the presence of gravity forces and the appearance of gas, friction, and inertia forces at time $t$,

$\mathrm{Q}_{\Delta U}(t)$ - thermal load resulting from the internal energy increase $\Delta U(t)$, at time $t$, of the elements through which part of thermal energy $E_{O}(t)$ penetrates, thus generating their load $Q_{O}(t)$,

$Q_{O}(t)$ - load of engine elements composing work spaces (combustion chambers) and other elements as a result of transmission of the dissipated (lost) energy to the environment at time $t$ (Fig. 1).

When studying these processes for an arbitrary time $t$, the objects of interest are random variables $Q_{t C}, Q_{t M}$ and $Q_{t D}$, which are, respectively, the values of the processes $\left\{Q_{C}(t)\right.$; $t \geq 0\},\left\{Q_{M}(t) ; t \geq 0\right\}$ and $\left\{Q_{D}(t) ; t \geq 0\right\}$.

In this interpretation the load is a result of the abovementioned energy conversion in each work space of the engine during its operation (Fig. 1). The thermal load leads to both linear and volumetric wear of tribological systems of the engine. Significant load and wear mainly concerns cylinder liners, cylinder head, and piston with rings. They are extremely high in case of cylinder liner walls in the combustion chambers and piston crowns, which are water cooled $[13,17]$. Remarkable loads are also recorded in outer layers of bushes and journals of both main and crankshaft bearings. They are caused by friction effects in bearings of this type. An additional load of these bearings, which can affect the rate of their wear, is mechanical load observed during detonation combustion. In general, the wear, both linear and volumetric, of crankshaft-piston assembly components which results from their load is a random process, as the loads of these components depend on the course of the combustion process in the engine work spaces. 


\section{COMBUSTION PROCESS AS THE CAUSE OF LOAD AND WEAR OF CRANKSHAFT- PISTON ASSEMBLY}

The combustion process, especially in the ship's main engine, should be considered a main cause of load and wear of elements composing its crankshaft-piston assembly. This wear, in both linear and volumetric form, is the cause of failures, frequently premature, of such important system components as pistons and main and crankshaft bearings. Both the load itself and its effects, in the form of wear and damages of crankshaft-piston assemblies, in this type of engines reveal random nature. The reason of this randomness is mainly a random course of fuel combustion in the work spaces of the abovementioned engines. This effect is extremely important in pressure charged engines, as engine charging enables to combust larger fuel doses in engine work spaces, which proportionally increases the average indicated pressure and, as a further consequence, the average useful pressure $[2,13,15]$. All this leads to higher torque (1) and higher engine power, without changing its rotational speed and/or cylinder displacement. The thermal load is also increased, without proportional increase of the maximum combustion pressure. That means that the mechanical load of the engine increases to a lesser degree, as compared to the thermal load. Smaller increase of the mechanical load results from the fact that charging the Diesel engine decreases the ignition delay time. This leads to softer engine operation, as the combustion begins with rapid oxidation of very small fuel portions. In this situation the maximum combustion pressure $\left(p_{\max }\right)$ increases more slowly than the average indicated pressure $\left(p_{i}\right)$ and the average useful pressure $\left(p_{e}\right)$. In Diesel engines the pressure build-up ratio for pressures generating thermal and mechanical stresses [2] can be defined as:

$$
\sigma_{p}=\xi \frac{p_{\max }}{p_{e}}
$$

where:

$\sigma_{p}$ - pressure build-up ratio,

$p_{\max }$ - maximum pressure in the engine work space (cylinder)

$p_{e}$ - average useful pressure in the engine cylinder

$\xi$ - pressure proportionality factor $(\xi<0,5)$.

Formula (8) shows that increasing the average useful pressure $\left(p_{e}\right)$ does not result in the same increase of the maximum combustion pressure $\left(p_{\max }\right)$ - for instance the appearance of a twice as high value of $p_{e}$ does not double the value of $p_{\max }[2,13,15]$. As a result, the mechanical stresses coming from mechanical loads are lower than those generated by thermal loads. In the Diesel engine the value of the arising maximum pressure, and consequently the maximum mechanical load of the crankshaft-piston assembly, can be limited by gradual injection of the fuel dose to the combustion chamber, done in such a way as to prevent rapid self-ignition of the entire fuel dose. This action is necessary as the oxidation rate of hydrocarbons increases significantly with the number of carbon (C) atoms in the fuel molecule, and those conditions make the appearance of the detonation combustion more likely. The intensity of detonation combustion increases for higher compression ratio $(\varepsilon)$. In fact, in Diesel engines the compression ratio is much higher than the level at which the detonation combustion can theoretically take place, but it does not appear in real engine operation. The reason is that in those engines the macro- and microstructure of the fuelair mixture at the initial time of self-ignition is far from ideal, which leads to insufficient amounts of oxygen in some areas of the combustion chamber and the creation of hydrocarbon peroxides in the first self-ignition centres, and to disintegration of $C_{n}$ molecules into molecular fractions, characterised by lower oxidation rate [2]. Therefore, in authors opinion, the following hypothesis $\mathbf{H}$ can be formulated: „despite a high combustion ratio $(\varepsilon)$, the detonation combustion does not take place, in general, in a Diesel engine because in engines of this type the fuel-air mixture at the initial time of selfignition has the macro- and microstructure which is far from ideal, due to the presence of areas in the combustion chamber with insufficient amounts of oxygen, which leads to the formation of hydrocarbon peroxides in first chemical reactions, accompanied by disintegration of $C_{n}$ molecules into molecular fractions characterised by lower oxidation rate". This hypothesis explains why the detonation combustion does not take place in the work spaces of correctly working Diesel engines. According to this hypothesis, it is highly unlikely that the flame front appearing just after the ignition delay will move at supersonic speed and thus create an exhaust gas shock wave, with the resultant excessive load of crankshaft-piston assembly bearings. However, combustion similar to the detonation combustion can appear, which is also very dangerous to the durability of bearings. The term proposed by the author for this type of combustion is quasidetonation combustion. It is characterised by such a rate of oxidation of combustible fuel particles which does not lead to the formation of a shock wave, but the pressure build-up ratio $\varphi_{p}$ in this combustion exceeds $1 \mathrm{MPa} / 1^{\circ} \mathrm{OWK}\left(1^{\circ}\right.$ of crankshaft revolution) [15]. This type of combustion can appear when the injection system works incorrectly, causing the ignition of the entire dose of the injected fuel. In this situation the phenomenon of flame front spreading at a speed nearing the speed of sound can be observed. The accompanying mass of the created exhaust gas may be characterised by high rates of temperature build-up $v_{T}=\mathrm{d} T / \mathrm{d} \alpha$ and pressure build-up $\varphi_{p}=\mathrm{d} p / \mathrm{d} \alpha$. In those conditions the pressure build-up rate $\left(\varphi_{p}\right)$ can exceed $1,2 \mathrm{MPa} / 1^{\circ} \mathrm{OWK}$.

Detonation combustion in Diesel engines can be avoided, for a given fuel, by decreasing the rate of injection and, consequently, fuel atomisation in engine cylinders. The lower limit of decreasing the fuel atomisation rate is the appearance of high opacity of the exhaust gas $[2,13,15]$.

During engine idling or partial load, large amounts of hard carbon deposits form as a result of insufficient atomisation $[13,17]$. These deposits, even after a relatively short time, can worsen the tightness of the exhaust valves and be a source of excessive pollution of the combustion chamber. The 
polluted combustion chamber has a smaller volume, which leads to the increase of the compression ratio $(\varepsilon)$, pressure $\left(p_{k}\right)$ and temperature $\left(T_{k}\right)$ at the end of compression of the fresh fuel charge. Larger $\varepsilon$ and, consequently, larger $p_{k}$ and $T_{\mathrm{k}}$, may decrease the earlier adjusted ignition delay, and thus quicken the self-ignition in the cylinder. As a result, especially in the engine full-load mode, the temperature and pressure of the exhaust gas in the combustion chamber are high and characteristic for quasi-detonation combustion. In those combustion conditions, carbon reach particles can be generated which delay the course of combustion and lead to the appearance of soot in the exhaust gas. [2]

In the Diesel engine, critical loads are thermal loads which generate mechanical stresses, for this reason bearing the name of thermal stresses. This is because a larger fuel dose leads to the formation of larger heat flux in the cylinder, with the resultant larger heat flux density and higher temperatures of the exhaust gas generated in fuel combustion. The amount of heat to be dissipated per unit time with respect to the combustion chamber surface area increases, as the temperature of the water used to cool the engine remains unchanged. That means that the thermal loads generated in combustion chamber elements by temperature gradients increase to the same extent. An unfavourable factor which additionally increases this load is the fact that the highest temperature increase is recorded when the work space of the cylinder has the volume equal to that of the combustion chamber. In this situation the heat transfer surface is the smallest and changes most slowly, as a result of which the piston crown, the upper part of the cylinder liner, and the inner wall of the cylinder head are the thermally heaviest loaded elements. [2, 13, 17]. Moreover, changes of thermal state of the engine, its wear, and incorrect adjustment of the injection apparatus can be a reason for partial (incomplete, imperfect) combustion which emits large amounts of harmful compounds $[1,12,13]$. The above considerations suggest that it is advisable to analyse such combustion process states as: $s_{1}$ - full combustion (complete and perfect), $s_{2}$ - imperfect combustion (with small amount of emitted harmful compounds), $s_{3}$ - partial combustion (imperfect and incomplete - with large amount of emitted harmful compounds), $s_{4}-$ quasi-detonation combustion. Evidently, during engine operation the above states take place with different probabilities. Assessing the probabilities for each of these process states to take place requires creating a combustion process model, the values of which are the above states $s_{i}, i=1,2,3,4[3,7,10,14]$.

\section{MODEL OF COMBUSTION PROCESS IN ENGINE CYLINDERS}

The analysis of the course of load and combustion processes shows that their states can be determined in such a way that the duration time of an arbitrary state existing at time $\tau_{n}$ and the state which will be available at time $\tau_{n+1}$ do not depend stochastically on states which earlier took place, nor time intervals of their existence $[5,6,7]$. That means that a semiMarkov model can be created for each of these processes [6,
$8,10]$.

It results from the theory of semi-Markov processes that creating a model of an arbitrary real process in the form of the semi-Markov process is possible once we describe its initial distribution $P_{i}(i=1,2, \ldots)$ and the functional matrix $\mathrm{Q}(t)[5$, $6,7,8,9,10,14]$.

Taking into account specific nature of the combustion process in work spaces (cylinders) of Diesel engines we can assume that the combustion process $\{X(t): t \geq 0\}$ with the set of states $S=\left\{s_{1}, s_{2}, s_{3}, s_{4}\right\}$ has the following initial distribution $[7,10]$ :

$$
P_{i}=P\left\{Y(0)=s_{i}\right\}=\left\{\begin{array}{l}
1 \text { for } i=1, \\
0 \text { for } i=2,3,4
\end{array}\right.
$$

and the functional matrix

$$
\mathbf{Q}(t)=\left[\begin{array}{cccc}
0 & Q_{12}(t) & 0 & 0 \\
0 & 0 & Q_{23}(t) & 0 \\
0 & Q_{32}(t) & 0 & Q_{34}(t) \\
Q_{41}(t) & Q_{42}(t) & 0 & 0
\end{array}\right]
$$

where:

$$
\begin{gathered}
Q_{i j}(t)=P\left\{X\left(\tau_{n+1}\right)=s_{j}, \tau_{n+1}-\tau_{n}<t \mid X\left(\tau_{n}\right)=s_{i}\right\} \\
s_{i}, s_{j} \in S ; i, j=1,2,3,4 ; i \neq j
\end{gathered}
$$

The initial distribution (9) results from the fact that after the production cycle the internal combustion engine should be ready to use $[6,7,10]$. Then the combustion process $\{X(t)$ : $t \geq 0\}$ (taking place in individual cylinders) should take such a course as to ensure the existence of state $s_{1}$ of this process. The appearance of the remaining states $s_{i} \in S(i=2,3,4)$ is connected with the decreased engine serviceability, first of all with incorrect operation of the injection apparatuses during engine operation.

The functional matrix (10) and the resultant graph of process state changes $\{X(t): t \geq 0\}$, shown in Fig. 2, reflect rational use of the engine, which has place when the user, after detecting any of engine states $s_{2}, s_{3}$ or $s_{4}$, undertakes a relevant technical action to repair the engine and thus restore its state $s_{1}$. When the state $s_{3}$ is detected by the diagnosing system, the engine user should eliminate causes of its appearance and restore the engine to the state $s_{1}$, i.e. to full (complete and perfect) combustion in cylinders. Such an action is not always possible in practice, hence the appearance of the state $s_{4}$ is quite frequent. It that situation the only rational action to be performed by the engine user is that leading to technical service which will allow to move the process back to the state $s_{1}$.

An important characteristic of the combustion process $\{X(t): t \geq 0\}$ in Diesel engine cylinders, which can be used to assess its course, is a set of conditional probabilities of process passing to particular states in the time not longer than $t$ :

$$
P_{i j}(t)=P\left\{X(t)=s_{j} \mid X(0)=s_{i}\right\},(i, j=1,2,3,4 ; i \neq j)
$$


This formula describes probabilities of passing from state $s_{i} \in S$ at time $t=0$ to state $s_{j} \in S$ at time $t \neq 0$.

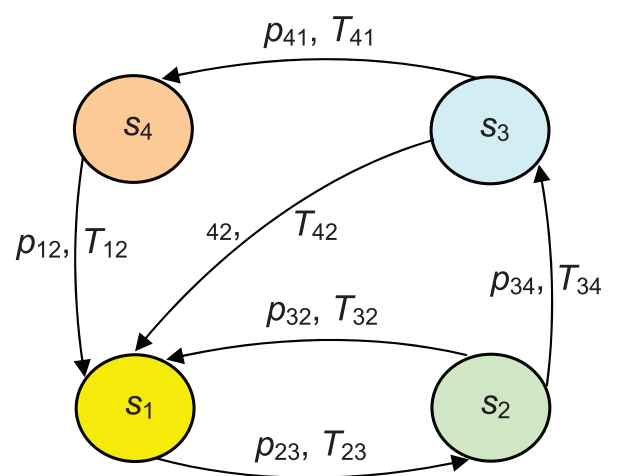

Fig. 2. Graph of combustion process state changes $\{X(t): t \geq 0\}$ in reciprocal engine: $s_{1}$ - full (complete and perfect) combustion, $s_{2}$ - imperfect combustion, $s_{3}$ - partial (incomplete and imperfect) combustion, $s_{4}$ - quasi-detonation combustion, $p_{i j}$ - probability of process passing from state $s_{i}$ to state $s_{j}$, $T_{i j}$ - time after which process passes from state $s_{i}$ to state $s_{j}(i, j=1,2,3,4 ; i \neq j)$

The probabilities $P_{i j}(t)$, formula (11), can be calculated, using the Kronecker delta symbol $\delta_{i j}$, from the following equation system [10]:

$$
P_{i j}(t)=\delta_{i j}\left[1-G_{i}(t)\right]+\sum_{k=1}^{4} \int_{0}^{t} P_{k j}(t-\zeta) d Q_{i k}(\zeta),
$$

which is operationally solved using the Laplace-Stieltjes transformation. In formula (12) $G_{i}(t)$ is the distribution function of the random variable $T_{j}$ representing the time duration of state $s_{i}(i=1,2,3,4)$ of the process $\{X(t): t \geq 0\}$, irrelevant of the state to which this state will pass. When analysed in a relatively long time interval $t$ (theoretically $t \rightarrow \infty)$, these probabilities tend to constant values, and after this time interval they constitute the limiting distribution [7, 10]:

$$
\left.\begin{array}{c}
P_{1}=\lim _{t \rightarrow \infty} P\left\{X(t)=s_{1}\right\}, P_{2}=\lim _{t \rightarrow \infty} P\left\{X(t)=s_{3}\right\}, \\
P_{3}=\lim _{t \rightarrow \infty} P\left\{X(t)=s_{3}\right\}, P_{4}=\lim _{t \rightarrow \infty} P\left\{X(t)=s_{4}\right\} .
\end{array}\right\}
$$

Detailed solutions of formula 12, which would be applicable in operating practice, can be obtained once the distributions $Q_{i j}(t)$ and $G_{i}(t)$ are known. These distributions can be calculated from the following relations $[7,10]$ :

$$
Q_{i j}(t)=p_{i j} F_{i j}(t), G_{i}(t)=\sum_{j=1}^{4} Q_{i j}(t)
$$

where:

$p_{i j}$ - probabilities of passing of the Markov chain $\left\{X\left(\tau_{n}\right): n=0\right.$, $1,2, \ldots\}$ placed into the process $\{X(t): t \geq 0\}$,

$F_{i j}(t)$ - distribution function of the random variable $T_{i j}$, representing the time duration of state $s_{i}$ provided that the next state is $s_{j}$ in the process $\{X(t): t \geq 0\},(i$, $j=1,2,3,4 ; i \neq j)$.

It results from formula (14) that the other characteristics of the process $\{X(t): t \geq 0\}$ are the quantities $Q_{i j}(t)$ and $G_{i}(t)$ representing, respectively, random variables $T_{i j}$ and $T_{i}$.

Of high importance for assessing correctness of the course of combustion process in Diesel engine cylinders in a relatively long time interval is the limiting distribution. The theory of semi-Markov processes says that this distribution, with the interpretation given by formula:

$$
P_{j}=\lim _{t \rightarrow \infty} P\left\{x(t)=s_{j}\right\} ; s_{j} \in S, j=\overline{1,4}
$$

can be calculated from the following relation $[7,10]$ :

$$
P_{j}=\frac{\pi_{j} E\left(T_{j}\right)}{\sum_{k=1}^{4} \pi_{k} E\left(T_{k}\right)} ; j=1,2,3,4
$$

where the limiting distribution $\pi_{j}, j=1,2,3,4$ of the Markov chain $\left\{X\left(\tau_{n}\right): n=0,1,2, \ldots\right\}$ placed into the process $\{X(t): t \geq 0\}$ fulfils the equation system $[7,10]$ :

$$
\begin{aligned}
& {\left[\pi_{1}, \pi_{2}, \pi_{3}, \pi_{4}\right] \cdot\left[\begin{array}{cccc}
0 & p_{12} & 0 & 0 \\
0 & 0 & p_{23} & 0 \\
0 & p_{32} & 0 & p_{34} \\
p_{41} & p_{42} & 0 & 0
\end{array}\right]=\left[\pi_{1}, \pi_{2}, \pi_{3}, \pi_{4}\right]} \\
& \pi_{1}+\pi_{2}+\pi_{3}+\pi_{4}=1
\end{aligned}
$$

From equations (16) and (17) the following form of the limiting distribution of the process $\{X(t): t \geq 0\}$ is obtained:

$$
\begin{aligned}
& P_{1}=\frac{p_{23} p_{34} p_{41} E\left(T_{1}\right)}{M} ; \quad P_{2}=\frac{E\left(T_{2}\right)}{M} ; \\
& P_{3}=\frac{p_{23} E\left(T_{3}\right)}{M} ; \quad P_{4}=\frac{p_{23} p_{34} E\left(T_{4}\right)}{M}
\end{aligned}
$$

where:

$$
M=p_{23} p_{34} p_{41} E\left(T_{1}\right)+E\left(T_{2}\right)+p_{23} E\left(T_{3}\right)+p_{23} p_{34} E\left(T_{4}\right)
$$

and: $P_{1}, P_{2}, P_{3}, P_{4}-$ probabilities that the process $\{X(t): t \geq 0\}$ will reach the state: $s_{1}, s_{2}, s_{3}, s_{4}$, respectively;

$E\left(T_{1}\right), E\left(T_{2}\right), E\left(T_{3}\right), E\left(T_{4}\right)$ - expected values of time durations of states: $s_{1}, s_{2}, s_{3}, s_{4}$, respectively;

$p_{\mathrm{ij}}-$ probabilities of process passing from state $s_{i}$ to state $s_{j}: i, j=1,2,3,4 ; i \neq j$.

The probability $P_{1}$ can be considered an indicator of correct fuel combustion in engine cylinders and, consequently, correct operation (work) of the engine, while the probabilities $P_{j}(j=2,3,4)$ will indicate incorrect fuel combustion in the cylinders and incorrect engine operation.

Rational action of the engine user should aim at preventing the appearance of state $s_{4}$ (then $P_{4}=0$ ) and take care that the time durations of states $s_{2}$ and $s_{3}$ of the fuel combustion process are as short as possible $\left(P_{2} \approx 0\right.$ and $\left.P_{3} \approx 0\right)$. This action requires relevant control of the combustion process during engine operation, for instance by following concepts presented in $[1$, $7,12,13]$, which will lead to the fuel combustion model $\{X(t)$ : $t \geq 0\}$ with the graph of state changes shown in Fig. 2 . 


\section{REMARKS AND CONCLUSIONS}

The presented probabilistic model of fuel combustion process in Diesel engine work spaces (cylinders) can be used for assessing the scale of adaptation of certain types of engines to complete and perfect, as well as detonation-free fuel combustion during relatively long time intervals of engine operation (work), and for assessing correctness of use of these engines in given operating conditions $[1,5,7,12,13]$. The model is a four-state model, worked out in the form a semiMarkov process, discrete in states and continuous in time. The values of this process are states: $s_{1}, s_{2}, s_{3}, s_{4}$ having the following interpretations: $s_{1}$ - full (complete and perfect) combustion, $s_{2}$ - imperfect combustion, $s_{3}-$ partial (incomplete and imperfect) combustion, $s_{4}-$ quasi-detonation combustion. Generally, it can be assumed that the lower the probability $P_{1}=P\left(s_{1}\right)$, the less correctly the engine is used. The probability $P_{1}$ can be interpreted as the probability of correct (faultless) engine operation.

The probabilities given by formulas (18) can be considered indices of Diesel engine reliability. Calculating exact values of these probabilities requires relevant field tests which would allow estimating the number of state changes in the presented model of fuel combustion in engine cylinders. The procedure should consist in evaluating the numbers $n_{i j}$, within a sufficiently long time interval $[0, t]$ and obtaining realisations $t_{i j}^{m}, m=1,2, \ldots, n_{i j}$ of random variables $T_{i j}$. This would make it possible to assess the distribution functions $F_{i j}(t)$, the probabilities $p_{i j}$, the expected values $E\left(T_{j}\right)$, and, finally, the probabilities that the combustion process stays in a given state $s_{i} \in \mathrm{S}(i=1,2,3,4)$.

The presented model of fuel combustion process in engine work spaces (cylinders) can be taken in to account when assessing the toxicity of exhaust gases from Diesel engines and the tendency to detonation combustion. This assessment is important, as otherwise it would not be possible to formulate an opinion on pro ecological values of this type of internal combustion engines and on the probability of detonation combustion in their cylinders. Better pro ecological values are confirmed by lower probabilities $\left(P_{i}, i=2,3\right)$, which can be considered probabilistic measures of emissions of harmful compounds contained in the exhaust gas. Low values of these probabilities mean that the emission of these compounds to the environment can be considered permissible. Moreover, a low value of the probability $P_{4}=P\left(s_{4}\right)$ suggests that the appearance of quasi-detonation combustion in this type of engines is not frequent and will not affect significantly the rate of wear of main and crankshaft bearings, and, consequently, their lifetime.

\section{BIBLIOGRAPHY}

1. Bielaczyc P., Merkisz J., Pielecha J.: Thermal state of the internal combustion engine vs. emission of harmful compounds (in Polish). Wydawnictwo Politechniki Poznańskiej, Poznań 2001.

2. Brun R.: High-speed Diesel engines (in Polish). WKiŁ, Warszawa 1973. Data on original edition: Science et Technique du Moteur Diesel Industriel et de Transport. Copyright by Societe des Editions Technip et Institut Francais du Petrole, Paris 1967.

3. Gichman I.I, Skorochod A.W.: Introduction to the theory of stochastic processes (in Polish). PWN, Warszawa 1968.

4. Girtler J.: Valuation method for operation of crankshaftpiston assembly in combustion engines in energy approach. Journal of POLISH CIMAC. - Vol. 6, no. 1 (2011), s. 89-98.

5. Girtler J.: Stochastic model of Diesel engine load spectrum (in Polish). Zagadnienia Eksploatacji Maszyn. PAS Quarterly, No. 1/97, 1994.

6. Girtler J.: Physical aspects of application and usefulness of semi-Markov processes for modeling the processes occurring in operational phase of technical objects. Polish Maritime Research, Vol. 11, No 3, September 2004.

7. Girtler J.: Controlling the process of marine internal combustion engine operation based on the diagnostic decision-making model (in Polish). Zeszyty Naukowe AMW, nr 100A, Gdynia 1989.

8. Girtler J.: Usefulness of semi-Markov processes as model of the operation processes for marine main engines and other machines of ship power plants. Journal of Polish CIMAC. Vol. 9, No 2, 2014, pp. 57 - 67.

9. Girtler J.: Issue of changes in technical states of a Diesel engine as the results of wear of its tribological systems. Zeszyty Naukowe Akademii Morskiej w Szczecinie, 31 (103), 2012., s. 77-82.

10. Grabski F.: Theory of semi-Markov processes of technical objects maintenance (in Polish). Zeszyty Naukowe AMW, nr 75A, Gdynia 1982.

11. Kozłowiecki H.: Bearings in reciprocal internal combustion engines (in Polish). Warszawa, WKiŁ 1982.

12. Merkisz J., Waligórski M., Babiak M., Kniaziewicz T.: Analysis of marine combustion engine processes with vibroacoustic methods for environment protection strategy. Combustion Engines No 2/2013 (153), pp. 28-39. 
13. Piotrowski I., Witkowski K.: Maintenance of marine internal combustion engines (in Polish). AM, Gdynia 2002.

14. Rozanov Ju.A.: Stacionarnye slučajnye processy. Fizmatgiz, Moskva 1963.

15. Wajand J.A.: Diesel engines (in Polish). WNT, Warszawa 1988.

16. Wiśniewski S.: Technical thermodynamics (in Polish). WNT, Warszawa 1995.

17. Włodarski J.K.: Reciprocal internal combustion engines. Tribological processes (in Polish). WKiŁ, Warszawa 1981.

\section{CONTACT WITH THE AUTHOR}

Jerzy Girtler

Gdańsk University of Technology

11/12 Narutowicza St.

80 - 233 Gdańsk

Poland 